The attitude of the medical profession in this country against circumcision has hardened in recent years, so much so that sincere and reasonable requests by the parents are sometimes turned down, which may cause distress and result in the mother canvassing other doctors or hospitals in search of a willing surgeon. The parents' desire for their baby to be circumcised may be based on firmly held beliefs concerning hygiene, national or religious convictions, or a desire for conformity among the males of the family. Our policy in such cases is to perform the operation if the parents still request it after a frank discussion of the medical viewpoint.

\section{Summary}

A technique for circumcising the newborn, using a plastic bell to protect the glans, which also acts as a guide to the amount of prepuce to be removed, is described. Excellent results have been obtained with this technique in over 150 cases and there have been no complications.

\section{REFERENCE}

Kariher, D. H., and Smith, T. W. (1956). Obstet. and Gynec., 7, 50.

\title{
Haemangiosarcomatosis: Two Cases Presenting as Haematological Problems
}

\author{
M. S. BOURNE,* M.в., CH.B.; T. A. COOK,* M.B., CH.B.; GEORGE WILLIAMS, $\dagger$ M.D., PH.D., M.C.PATH.
}

According to Willis (1960), haemangiosarcoma is a "very rare" tumour. However, within four years two cases involving this neoplasm have been investigated in the Department of Clinical Haematology at Manchester Royal Infirmary ; their details are presented in this paper.

\section{Case 1}

A 33-year-old housewife developed pleuritic pain in February 1961. A month later she felt tired and ill, with pains in the limbs, and had become pale and very dyspnoeic. On admission to a local hospital in May she was febrile and the tip of the spleen was just palpable. A moderate normochromic anaemia was present $(\mathrm{Hb} 7.1$ g. $/ 100 \mathrm{ml}$.) with a small number of red-cell and white-cell precursors in the peripheral blood. The total white-cell count and platelet count were normal. All investigations, including blood urea, liverfunction tests, blood culture, and a search for L.E. cells were negative. No definite diagnosis was reached.

Prednisolone, penicillin, and blood transfusions were given. She improved and was discharged home on a reduced steroid dosage. Five days later, however, she was readmitted with epistaxis, purpura, romiting, and pain in the left arm. The haemoglobin level had fallen to $4.9 \mathrm{~g} . / 100 \mathrm{ml}$. Steroid therapy was continued and she was transfused repeatedly. Four weeks later, when she was transferred to the Royal Infirmary, Manchester, there was still extensive purpura. In spite of the blood she had received the haemoglobin was still only $7.6 \mathrm{~g} . / 100 \mathrm{ml}$. The platelet count had fallen to $40,000 / \mathrm{c} . \mathrm{mm}$., and the leucocytes numbered $18,000 / \mathrm{c}$.mm. There was still a leucoerythroblastic peripheral blood picture.

All investigations remained negative. A sternal marrow specimen was unhelpful. However, a radiological skeletal survey revealed multiple osteolytic foci indicating widespread tumour involvement. She continued to receive steroids and blood transfusions ; in addition, intravenous nitrogen mustard therapy $-2 \times 6 \mathrm{mg}$. Trillekamin (trimustine hydrochloride)-was given. There was no response ; her condition deteriorated and 14 days later she died.

Pathology.-Necropsy confirmed the presence of haemorrhagic and partly necrotic tumour tissue in the upper end of the femora, humeri (with a pathological fracture through a deposit in the proximal left humerus), thoracic vertebrae, and throughout the rib cage. Tumour deposits were also present in the liver, spleen, right ovary, and right atrium. The lymph nodes were not involved.

\footnotetext{
* Registrar, Department of Clinical Haematology, Manchester Royal Infirmary,
}

+ Senior Lecturer, Department of Pathology, University of Manchester.
None of these tumour deposits could be confidently recognized as the primary.

Histology.-Sections from various sites showed a pleomorphic neoplasm comprising spindle and round-cell forms with reticular nuclei, few mitoses, but occasional binucleate cells. The tumour cells were arranged as compact masses often lining prominent vascular spaces (Fig. 1). In the spleen there were foci of myeloid metaplasia in the tumour tissue.

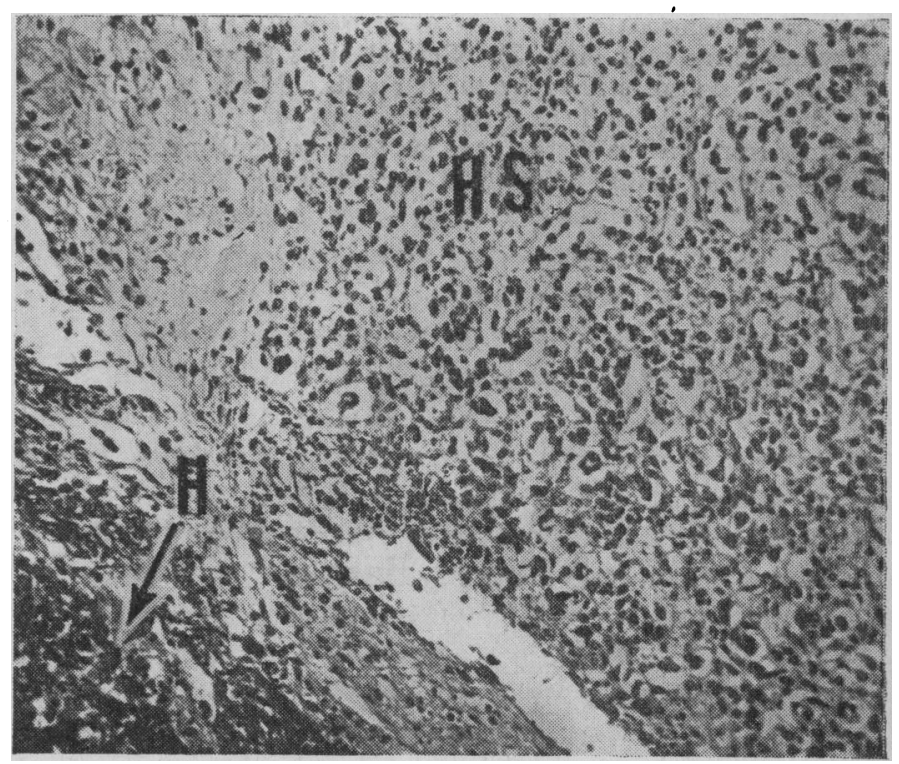

FIG. 1.-Case 1. Section of spleen showing edge of haemorrhagic area (H) lined by haemangiosarcomatous tissue (HS). (H. and E. $\times 170$.)

\section{Case 2}

A 71-year-old woman was seen in the out-patient clinic, where she gave a five-month history of pain in the left hypochondrium She was found to have an enlarged, unusually hard spleen, a moderate normochromic anaemia, and thrombocytopenia (platelet count 41,000/c.mm.). A small number of red-cell and white-cell precursors were present in the peripheral blood. Two months later, in January 1964, the abdominal pain had become more severe and 
she was admitted to hospital, where splenectomy was carried out. At operation, tumour nodules were seen in the liver but not elsewhere. Post-operatively the platelet count rose to normal levels, but she remained ill and lost weight. A month after the operation enlarged lymph nodes appeared in the right supraclavicular fossa. Six months post-operatively she died at home. A diagnosis of haemangiosarcoma was made from histological examination of the spleen.

Pathology.-The cut surface of the liver showed extensive tumour involvement of both lobes and a mottled haemorrhagic appearance. Enlarged lymph nodes in the porta hepatis, mesentery, along the lesser gastric curvature, and the para-aortic chains had a similar haemorrhagic cut surface. The marrow of many vertebrae, both femora, the sternum, and the ribs was also extensively invaded by tumour.

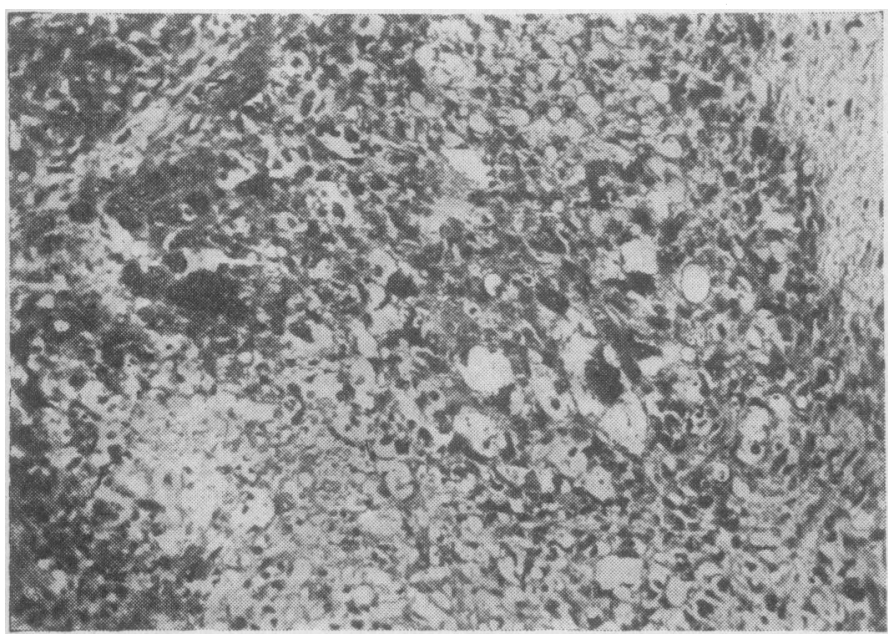

FIG. 2.-Case 2. Section from resected spleen showing haemorrhagic pleomorphic haemangiosarcoma. (H. and E. $\times 170$.)

Histology.-Sections of resected spleen showed extensive replacement by pleomorphic neoplasm composed of spindle cells and numerous giant cells (Fig. 2). Several areas showed rudimentary thin-walled sinusoids lined by tumour cells. Much of the tumour was haemorrhagic and necrotic. Sections of tumour taken at necropsy from various sites-for example, liver, bone-marrow, lymph nodes-showed similar histological appearances.

\section{Discussion}

In both cases the distribution of the metastases is consistent with blood-spread dissemination from a primary tumour, as in the cases of Tibbs (1953), Raven and Christie (1953), and Shore (1957). In Case 2 the spleen may have been primarily involved, as was alleged in the cases of Wright (1928) and those of several subsequent authors; there was no evidence to support an origin in widespread pre-existing angiomata.

Histologically, in both cases and regardless of site, the tumour consisted solely of neoplastic vascular tissue. As such, it was regarded as haemangiosarcoma and not merely vascular proliferation in another tumour type. There was close similarity to many previously described cases and the diagnostic criteria of Stout (1943) were fulfilled.

The leucoerythroblastic blood picture is presumably the result of bone-marrow infiltration by tumour. Two other haematological features have been described in some previous cases-haemopoiesis in the tumour vascular spaces and megaloblastic anaemia. The former was seen in the spleen in Case 1 ; the latter was present in neither. Thrombocytopenia, a significant feature in both cases, has not been previously noted in this form of malignancy.

\section{Summary}

Two cases of haemangiosarcoma are described in women aged 33 and 71 . Both cases presented as haematological problems, one with refractory anaemia, the other with splenomegaly, each with a leucoerythroblastic peripheral blood picture. In neither case could the primary tumour be confidently diagnosed, but the widespread nature of the tumour deposits suggested blood-stream dissemination.

\section{REFERENCES}

Raven, R. W., and Christie, A. C. (1953). Brit. F. Surg., 41, 483.

Shore, J. H. (1957). F. Path. Bact., 74, 289.

Stout, A. P. (1943). Ann. Surg., 118, 445

Tibbs, D. (1953). Brit. ₹. Surg., 40, 465.

Willis, R. A. (1960). Pathology of Tumours, 3rd ed., p. 704. Butterworth, London.

Wright, A. W. (1928). Amer. F. Path., 4, 507.

\section{Medical Memoranda}

\section{Toxic Psychosis Caused by Inhalation of Petrol Fumes}

\section{Brit. med. F., 1965, 2, 276-277}

Drug addiction among adolescents has been receiving much publicity in recent years, but as yet only a few cases of the sniffing of petrol vapour have been published. Since 1951 fifteen cases in all have been reported (Clinger and Johnson, 1951 ; Faucett and Jensen, 1952 ; Nitsche and Robinson, 1959 ; Pruitt, 1959 ; Edwards, 1960 ; Oldham, 1961 ; Lawton and Malmquist, 1961 ; Easson, 1962 ; Gold, 1963 ; Tolan and Lingl, 1964 ; Sanderson, Campbell, and Laverty, 1963).

\section{CASE Report}

A 14-year-old boy was given the job of mowing his school lawn and when filling up the mower with petrol found that inhaling the vapour made him feel " less nervy and edgy." He was the fourth child of an unhappy home. Father was an affable garage mechanic known to have been having an affair with another woman for many years. Mother, possibly as a result of this, was a harsh, hardened, embittered woman. The boy had always been regarded at school as being rather sensitive and tense and had not found school life too congenial, or lessons too easy. He had welcomed the opportunity to be on his own to mow the lawn. From inhaling the petrol vapour when filling the school lawn-mower he took to carrying a petrol lighter around so that he could at other times inhale petrol fumes. After four months of this habit he arrived home late one winter evening very breathless, hot, flushed, and frightened. $\mathrm{He}$ chattered away continuously about foxes, which he said he saw all around him and he feared were going to attack him. He had been sniffing petrol in a nearby barn when he had first begun to see the foxes.

His parents, particularly his father, as a result of what had happened began to take more interest in him. For a few weeks he was given a long-acting phenobarbitone Spansule every morning, though his acutely disturbing hallucinatory symptoms had cleared up the same night. So far as can be ascertained he has not sniffed petrol fumes for the last two years. He appeared to be happier at school for the remaining few months before he left, and he is now 